\title{
Genetic evaluation of AMPD1, CPT2, and PGYM metabolic enzymes in patients with chronic fatigue syndrome
}

\author{
P.E. Maltese ${ }^{1}$, L. Venturini ${ }^{2}$, E. Poplavskaya ${ }^{3}$, M. Bertelli ${ }^{1}$, S. Cecchin ${ }^{1}$, \\ M. Granato ${ }^{1}$, S.Y. Nikulina ${ }^{3}$, A. Salmina ${ }^{3}$, N. Aksyutina ${ }^{3}$, E. Capelli ${ }^{4}$, \\ G. Ricevuti ${ }^{2}$ and L. Lorusso ${ }^{5}$
}

${ }^{1}$ MAGI Non-Profit Human Medical Genetics Institute, Rovereto, TN, Italy ${ }^{2}$ Cellular Pathophysiology and Clinical Immunology Laboratory, Department of Internal Medicine and Therapeutics, University of Pavia, Pavia, Italy

${ }^{3}$ Department of Internal Diseases N.1, Krasnoyarsk State Medical University, Krasnoyarsk, Russia

${ }^{4}$ Immunology and Genetic Analysis Laboratory,

Department of Earth and Environmental Sciences, University of Pavia, Pavia, Italy

${ }^{5}$ Department of Neurology, Mellino Mellini Hospital, Chiari, BS, Italy

Corresponding author: P.E. Maltese

E-mail: paolo.maltese@assomagi.org

Genet. Mol. Res. 15 (3): gmr.15038717

Received April 19, 2016

Accepted July 22, 2016

Published July 29, 2016

DOI http://dx.doi.org/10.4238/gmr.15038717

Copyright (C) 2016 The Authors. This is an open-access article distributed under the terms of the Creative Commons Attribution ShareAlike (CC BY-SA) 4.0 License.

\begin{abstract}
Chronic fatigue syndrome (CFS) is a disease that can seriously impair one's quality of life; patients complain of excessive fatigue and myalgia following physical exertion. This disease may be associated with abnormalities in genes affecting exercise tolerance and physical performance. Adenosine monophosphate deaminase
\end{abstract}


(AMPD1), carnitine palmitoyltransferase II (CPT2), and the muscle isoform of glycogen phosphorylase (PYGM) genes provide instructions for producing enzymes that play major roles in energy production during work. The aim of this study was to look for evidence of genotypeassociated excessive muscle fatigue. Three metabolic genes (AMPD1, $C P T 2$, and $P Y G M$ ) were therefore fully sequenced in 17 Italian patients with CFS. We examined polymorphisms known to alter the function of these metabolic genes, and compared their genotypic distributions in CFS patients and 50 healthy controls using chi-square tests and odds ratios. One-way analysis of variance with F-ratio was carried out to determine the associations between genotypes and disease severity using $\mathrm{CF}$ scores. No major genetic variations between patients and controls were found in the three genes studied, and we did not find any association between these genes and CFS. In conclusion, variations in $A M P D 1, C P T 2$, and PGYM genes are not associated with the onset, susceptibility, or severity of CFS.

Key words: $A M P D 1 ; C P T 2 ; P G Y M$; Chronic fatigue syndrome; Polymorphism

\section{INTRODUCTION}

After decades of debates, numerous scientific publications, changes in names, and redefinition of diagnostic criteria, chronic fatigue syndrome (CFS) remains an obscure, misunderstood, and underdiagnosed disease. Etiological factors for this disease are still unknown, and many patients are only diagnosed after long periods of suffering and misunderstandings.

Despite continued efforts to elucidate the causes of this disease, CFS is still diagnosed by exclusion. The current diagnostic criteria for CFS are defined as follows: impaired function persisting for at least 6 months, post-exertional malaise (physical or cognitive exertion), unrefreshing sleep, cognitive impairment, and orthostatic intolerance.

Several genetic causes for CFS have been suggested in various studies. The aforementioned symptoms, especially myalgia and exercise intolerance, could be associated with dysfunctions in genes involved in metabolic pathways, especially when these symptoms are present in young subjects. Genetic variations in myoadenylate deaminase (AMPD1), carnitine palmitoyltransferase II (CPT2), and muscle glycogen phosphorylase (PYGM) are known to cause such symptoms, which led us to investigate their involvements in CFS.

A common mild form of genetic myopathy is AMPD1-deficiency myopathy (OMIM 615511). The AMPD1 gene encodes for an enzyme found in the skeletal muscle, which is involved in energy production (Morisaki et al., 1992). It converts adenosine monophosphate to inosine monophosphate, releasing an ammonia molecule during the process (Lucia et al., 2009). To produce energy, cells convert sugar, fat, and protein into adenosine triphosphate (ATP) via the mitochondria. Impaired ATP production and recycling has been demonstrated in CFS patients (Myhill et al., 2009). However, the exact genetic basis for CFS is still unknown.

A frequent $A M P D 1$ gene polymorphism is a nonsense $\mathrm{C}$ to $\mathrm{T}$ transition in nucleotide 34 (c. $34 \mathrm{C}>\mathrm{T})$ in exon 2, otherwise known as p. $\left(\mathrm{G} \ln 12^{*}\right)$. This SNP converts the CAA codon

Genetics and Molecular Research 15 (3): gmr.15038717 
into the premature stop-codon TAA (Cięszczyk et al., 2011). Given that the truncated protein cannot fulfill its energy production role in skeletal muscle cells, it was postulated that this mutation may be associated with CFS (Isackson et al., 2006). The latest nomenclature refers to this stop-gained-near-splice mutation as the c.133C > T transition, or p.(Gln45*), rs17602729, which is used henceforth in this paper.

Pain, stiffness, cramps, and fatigue after strenuous exercise or periods without food may cause myopathy related to mutations in the CPT2 gene (Thuillier et al., 2003). This gene encodes carnitine palmitoyltransferase II, a peripheral inner mitochondrial membrane protein involved in $\beta$-oxidation of fatty acids (Taroni et al., 1992); it catalyzes the transesterification of palmitoylcarnitine back into palmitoyl-CoA, an activated substrate for $\beta$-oxidation in the mitochondrial matrix (Tol, 1975). Long-chain fatty acids must be attached to carnitine to enter mitochondria (Gellera et al., 1994). Once inside, carnitine palmitoyltransferase 2 removes the carnitine, and adds coenzyme A (Finocchiaro et al., 1991). Long-chain fatty acids need to be joined to coenzyme A before they can be metabolized to produce energy (Kerner and Hoppel, 2000).

Reduced energy production due to genetic CPT2 deficiency (infantile OMIM 600649 and late-onset OMIM 255110) can lead to muscle pain and weakness, low blood sugar (hypoglycemia), and low levels of ketones, which are products of fat metabolism (hypoketosis) (Finocchiaro et al., 1991). Fatty acids and long-chain acylcarnitines (fatty acids still attached to carnitine) may also build up in cells, resulting in damages to the liver, the heart, and the muscles (Longo et al., 2006). This is the most common inherited disorder of lipid metabolism affecting skeletal muscles in adults, and is the most frequent cause of hereditary myoglobinuria (Corti et al., 2008).

As of March 2015, 99 mutations have been listed in the professional Human Gene Mutation Database (HGMD; http://www.biobase-international.com/product/hgmd). The common non-synonymous polymorphisms c.1102G $>$ A or p.(Val368Ile) (rs1799821) and c.1939A > G or p.(Met647Val) (rs1799822) have been linked to CPT2 deficiency. These genetic abnormalities alone do not directly cause the disorder. However, they seem to exacerbate enzyme dysfunctions when combined with one or more primary $C P T 2$ mutations (Bonnefont et al., 2004).

Carnitine metabolic impairments have also been observed in CFS (Kuratsune et al., 1994), and some clinicians prescribe 1-carnitine dietary supplements as therapies for their patients (Huang et al., 2013; Lee et al., 2014; Cruciani et al., 2015). Symptoms such as exercise intolerance manifesting as acute crises of early fatigue and contractures, sometimes in combination with rhabdomyolysis and recurrent myoglobinuria, are also associated with McArdle disease (myophosphorylase deficiency, OMIM 232600) (McArdle, 1951), a disorder caused by homozygous or compound heterozygous mutations in the PYGM gene. This gene encodes a muscle glycogen phosphorylase that catalyzes the breakdown of glycogen to glucose-1-phosphate. The PYGM gene contributes to the body's energy supply by breaking down glycogen in the muscles (Tsujino et al., 1995). To date, 146 mutations in the PYGM gene have been described in the professional HGMD. Among these, the most common functional mutations include p.(Arg50*) (rs116987552) (originally reported as Arg49*) (Tsujino et al., 1993), which results in a premature termination codon that decreases enzyme production. In addition, p.(Trp798Arg) (rs119103258) (originally reported as Trp797Arg), a polymorphism associated with reduction in enzyme activity, is also associated with the disease (Rubio et al., 2000).

Genetics and Molecular Research 15 (3): gmr.15038717 
At the Department of Neurology in Mellini Hospital (Chiari, Brescia Province, Italy), 17 patients with post-exertional myopathy and exercise intolerance symptoms were diagnosed with CFS. The main aim of this study was to sequence AMPD1, CPT2, and PYGM in all subjects to identify rare genetic variants in probable CFS patients, and to determine if they were affected with one of the genetic diseases mentioned above.

To gain a greater understanding of their possible roles in manifestation of symptoms and pathogenesis of CFS, genetic distributions of AMPD1, CPT2, and PYGM polymorphisms were also determined in 50 healthy individuals.

\section{MATERIAL AND METHODS}

\section{Genetic study}

Blood from 17 CFS patients and 50 healthy controls was sent to the MAGI laboratory (Magi's Lab, Rovereto, TN, Italy), where DNA was extracted using the salting-out method (Blood DNA kit E.N.Z.A., Omega Bio-Tek). The coding and adjacent intron regions of the AMPD1 (NM_000036.2; 16 exons), CPT2 (NM_000098.2; 5 exons), and PYGM (NM_005609.2; 20 exons) genes were analyzed by polymerase chain reaction (PCR) and direct sequencing using a Beckman Coulter CEQ 8000 sequencer (Beckmann Coulter, Milano, Italy). We analyzed the DNA from 50 healthy controls, and determined the distributions of $A M P D 1$ p.(Gln45*) and CPT2 p.(Met647Val) polymorphisms by Tai-I and Psc-I restriction enzyme analysis, respectively. The CPT2 p.(Val368Ile) polymorphism was studied by direct sequencing of the target sequence. No genetic studies were performed for the PYGM gene in the control group as no polymorphisms were found in the CFS patients. The laboratory protocols used for genotyping are available on request.

\section{Statistical analysis}

Unless otherwise indicated, data are reported as means \pm SD or $95 \%$ confidence interval. The chi-square test was used to determine whether the distributions of AMPD1 and CPT2 polymorphisms differed significantly between the patients and controls. The odds ratio was used to measure the association between CFS and the observed genotype frequencies. Statistical significance was set at $\mathrm{P}<0.05$ for both genes. Haplotype frequencies of cases and controls of two CPT2 polymorphisms, p.(Val368Ile) and p.(Met647Val), were determined using the Haploview software version 4.2 (http://www.broadinstitute.org/haploview/ haploview) (Barrett et al., 2005), and $\chi^{2}$ statistics were used to compare the distribution between populations. We also investigated the associations between polymorphisms in the CPT2 p.(Val368Ile), p.(Met647Val), and AMPD1 p.(Gln45*) genes and the CF score. These associations were analyzed using one-way analysis of variance (ANOVA) with F-ratio. All statistical analyses were performed with the MedCalc software (Mariakerke, Belgium).

\section{Subjects}

The 1994 International Consensus Criteria were used for diagnosis of CFS (Fukuda et al., 1994). Fatigue was assessed with a self-report questionnaire that included the Checklist Individual Strength-20 (CIS-20) subscales on "fatigue severity" (8 items) and "concentration

Genetics and Molecular Research 15 (3): gmr.15038717 
problems" (5 items). The cut-off for severe fatigue was set at 26 (CF score range 0-26) (Wessely and Powell, 1989).

The Italian patients enrolled in this study included 6 males and 11 females, ranging between 18 and 51 years of age ( $30 \pm 10.45$ years). Onset of CSF was between 7 and 41 years of age in these individuals ( $16 \pm 7.94$ years).

A questionnaire was specifically prepared by geneticists at MAGI, and was sent to the patients' doctors, who administered it via interview. The questions were as follows:

1) Age of onset of disorder

2) What are the main symptoms? CFS was diagnosed based on which symptoms?

3) Other symptoms such as:

- depression

- cognitive disorders

- orthostatic hypotension, tachycardia or other cardiac disorders

- other disorders of the autonomic nervous system

4) If other parameters were evaluated, was there any evidence of abnormal values, such as high levels of circulating immune complexes, lymphocytosis, increased immunoglobulin $\mathrm{G}$, increased alkaline phosphatase, total cholesterol, and lactate?

(If possible, please indicate laboratory results).

5) Do any relatives have similar symptoms?

We also examined a control group of 50 healthy Italian subjects ( 25 men and, 25 women; aged $43.6 \pm 9.1$ years), who were selected from donors recruited for research studies; selection criteria for this group were a declared sport attitude ( $\geq 2$ days sport activity per week), and a mean age greater than the maximum age of CFS onset in our patients.

\section{Ethical considerations}

All patients volunteered to participate in the study, with the support and approval of the CFS Patients Association (AMCFS; http://www.associazionecfs.it/) as further protection and guarantee of patients' rights. Written informed consent was obtained from all 67 subjects prior to study enrolment. In addition, permission was given by all subjects to use their clinical and genetic data for publication and research. Guidelines from the Ethics Committee for the present study stated that if anonymized or in aggregate, diagnostic data bearing patients' consent for research does not require approval by the Ethics Committee as the data cannot be traced back to the persons involved.

\section{RESULTS}

The questionnaire prepared by geneticists of MAGI was administered by interview. Viral infection was the most common factor triggering CFS (13/17 patients, 76\%), followed by unknown causes $(2 / 17,12 \%)$, HBV vaccine $(1 / 17,6 \%)$, and exercise $(1 / 17$, $6 \%)$. CF score ranged from 20 to $26(23 \pm 1.67)$ in our patients. Myalgia was reported by $12 / 17(71 \%)$ of the patients, and was absent in 5/17 (29\%) of the patients. Duration of CFS was 1 to 32 years $(14 \pm 8.18$ years). Cognitive impairments involving problems with memory and concentration, learning difficulties, and incapacity to solve simple problems was reported by $7 / 17$ (41\%) patients. Clinical and laboratory characteristics of cases are reported in Table 1.

Genetics and Molecular Research 15 (3): gmr.15038717 
Table 1. Clinical and laboratory features of cases.

\begin{tabular}{|c|c|c|c|c|c|c|c|c|c|c|c|c|}
\hline Case & $\begin{array}{l}\text { Affected } \\
\text { relatives }\end{array}$ & $\begin{array}{c}\begin{array}{c}\text { Age of } \\
\text { onset } \\
\text { (years) }\end{array} \\
\end{array}$ & $\begin{array}{c}\text { Age } \\
\text { (years) }\end{array}$ & $\begin{array}{c}\text { CF score } \\
(0-26)\end{array}$ & Myalgia & $\begin{array}{c}\text { Recurring } \\
\text { fever }\end{array}$ & $\begin{array}{c}\text { Cognitive } \\
\text { impairment }\end{array}$ & Depression & $\begin{array}{l}\text { Trigger } \\
\text { factors }\end{array}$ & $\begin{array}{c}C P T 2 \\
\text { p.(Val368Ile) }\end{array}$ & $\begin{array}{c}C P T 2 \\
\text { p.(Met647 } \\
\text { Val) } \\
\end{array}$ & $\begin{array}{c}\text { AMPD1 } \\
\text { p.(Gln45*) }\end{array}$ \\
\hline 1 & No & 10 & 24 & 23 & No & No & Yes & No & Infection & Ile/lle & Met/Val & $\mathrm{Gln} / *$ \\
\hline 2 & Yes & 29 & 49 & 25 & Yes & No & No & No & Exercise & Ile/Ile & Met/Val & $\mathrm{Gln} / \mathrm{G} \ln$ \\
\hline 3 & No & 41 & 45 & 22 & Yes & Yes & Yes & No & Infection & $\mathrm{Val} / \mathrm{Val}$ & Met/Met & $\mathrm{Gln} / \mathrm{Gln}$ \\
\hline 4 & No & 12 & 32 & 26 & Yes & No & Yes & No & Vaccine & Val//le & Met/Met & $\mathrm{Gln} / \mathrm{Gln}$ \\
\hline 5 & No & 10 & 35 & 22 & Yes & No & No & No & Infection & $\mathrm{Val} / \mathrm{Ile}$ & Met/Met & $\mathrm{Gln} / *$ \\
\hline 6 & No & 16 & 26 & 24 & No & Yes & No & Yes & Unknown & $\mathrm{Val} / \mathrm{Ile}$ & Met/Met & $\mathrm{Gln} / \mathrm{G} \ln$ \\
\hline 7 & Yes & 7 & 25 & 24 & Yes & No & Yes & No & Unknown & $\mathrm{Val} / \mathrm{lle}$ & Met/Val & $\mathrm{Gln} / *$ \\
\hline 8 & No & 17 & 22 & 25 & Yes & Yes & No & No & Infection & $\mathrm{Val} / \mathrm{Val}$ & Met/Val & $\mathrm{Gln} / *$ \\
\hline 9 & No & 16 & 35 & 24 & No & No & No & Yes & Infection & $\mathrm{Val} / \mathrm{Val}$ & Met/Met & $\mathrm{Gln} / \mathrm{Gln}$ \\
\hline 10 & No & 13 & 43 & 21 & No & No & No & No & Infection & $\mathrm{Val} / \mathrm{Val}$ & Met/Met & $\mathrm{Gln} / \mathrm{Gln}$ \\
\hline 11 & No & 13 & 22 & 25 & Yes & Yes & Yes & Yes & Infection & $\mathrm{Val} / \mathrm{Val}$ & Met/Met & $\mathrm{Gln} / \mathrm{G} \ln$ \\
\hline 12 & No & 14 & 32 & 23 & Yes & Yes & No & No & Infection & Ile/Ile & Met/Met & $\mathrm{Gln} / *$ \\
\hline 13 & Yes & 14 & 44 & 23 & No & Yes & No & No & Infection & Val/lle & Met/Val & Gln/Gln \\
\hline 14 & No & 14 & 50 & 24 & Yes & Yes & No & No & Infection & Ile/Ile & $\mathrm{Val} / \mathrm{Val}$ & $\mathrm{Gln} / \mathrm{Gln}$ \\
\hline 15 & No & 13 & 32 & 22 & Yes & No & Yes & No & Infection & Ile/Ile & Met/Val & $\mathrm{Gln} / \mathrm{G} \ln$ \\
\hline 16 & No & 14 & 24 & 21 & Yes & Yes & Yes & No & Infection & $\mathrm{Val} / \mathrm{lle}$ & Met/Val & $\mathrm{Gln} / \mathrm{Gln}$ \\
\hline 17 & No & 14 & 27 & 20 & Yes & Yes & No & No & Infection & Val/lle & Met/Met & $\mathrm{Gln} / *$ \\
\hline
\end{tabular}

Direct sequencing analysis on our patients did not show any major nucleotide variations in AMPD1, CPT2, or PGYM genes; only one synonymous variation, c.1806T > C or p.(Phe602Phe) (rs147953465) in the CPT2 gene was found in case 11.

Non-synonymous CPT2 p.(Val368Ile), p.(Met647Val), and AMPD1 p.(Gln45*) polymorphisms were detected as expected. Analysis on the frequency distributions was conducted using a case-control approach, extending genetic analysis to 50 healthy subjects. As shown in Table 2, we did not find any differences between the two populations. In addition, haplotype approach analysis on two $C P T 2$ polymorphisms in cases and controls did not reveal any differences in the frequency distributions between patients and controls (Table 3).

No significant variations in $\mathrm{CF}$ scores were found with respect to genotype for $A M P D 1$ p. $($ Gln 45*) $($ F-ratio $=0.38, \mathrm{P}=0.55), C P T 2$ p. $($ Val368Ile $)($ F-ratio $=0.19, \mathrm{P}=0.82)$, and p.(Met647Val) $(\mathrm{F}$-ratio $=0.168, \mathrm{P}=0.85)$ polymorphisms.

ANOVA revealed that EBV-negative patients demonstrated significantly higher CF scores (F-ratio $=6.16, \mathrm{P}=0.02$ ) as compared to those with a history of mononucleosis (high levels of IgG or IgM antibodies for EBV in their last blood test) (Figure 1).

Table 2. Distribution of polymorphisms in cases and controls.

\begin{tabular}{|c|c|c|c|c|c|c|}
\hline \multicolumn{7}{|c|}{ AMPD1 p.(Gln $\left.45^{*}\right)$} \\
\hline \multirow[t]{2}{*}{ Genotype } & \multirow[t]{2}{*}{ Cases [N (\%)] } & \multirow[t]{2}{*}{ Controls [N (\%)] } & \multicolumn{2}{|c|}{$\mathrm{G} \ln / \mathrm{G} \ln v s \mathrm{G} \ln / *$} & \multicolumn{2}{|c|}{$\mathrm{G} \ln / \mathrm{G} \ln v s * / *$} \\
\hline & & & OR & $\mathrm{P}<0.05$ & OR & $\mathrm{P}<0.05$ \\
\hline $\mathrm{Gln} / \mathrm{G} \ln$ & $11(65 \%)$ & $36(72 \%)$ & 0.61 & 0.42 & 1.58 & 0.77 \\
\hline $\mathrm{Gln} / *$ & $6(35 \%)$ & $12(24 \%)$ & \multicolumn{4}{|c|}{$\chi^{2} \mathrm{P}$ value } \\
\hline$* / *$ & 0 & $2(4 \%)$ & & & & \\
\hline \multicolumn{7}{|c|}{ CPT2 p.(Val368Ile) } \\
\hline \multirow[t]{2}{*}{ Genotype } & \multirow[t]{2}{*}{ Cases [N (\%)] } & \multirow[t]{2}{*}{ Controls [N (\%)] } & \multicolumn{2}{|c|}{$\mathrm{Val} / \mathrm{Val}$ vs Val//le } & \multicolumn{2}{|c|}{ Val/Val vs Ile/Ile } \\
\hline & & & OR & $\mathrm{P}<0.05$ & OR & $\mathrm{P}<0.05$ \\
\hline $\mathrm{Val} / \mathrm{Val}$ & $5(29 \%)$ & $9(18 \%)$ & 2.3 & 0.23 & 1.33 & 0.71 \\
\hline Val/Ile & $7(42 \%)$ & $29(58 \%)$ & \multicolumn{4}{|c|}{$\chi^{2} \mathrm{P}$ value } \\
\hline Ile/Ile & $5(29 \%)$ & $12(24 \%)$ & & & & \\
\hline \multicolumn{7}{|c|}{ CPT2 p.(Met647Val) } \\
\hline \multirow[t]{2}{*}{ Genotype } & Cases [N (\%)] & Controls [N (\%)] & \multicolumn{2}{|c|}{ Met/Met $v s$ Met/Val } & \multicolumn{2}{|c|}{ Met/Met $v s \mathrm{Val} / \mathrm{Val}$} \\
\hline & & & OR & $\mathrm{P}<0.05$ & OR & $\mathrm{P}<0.05$ \\
\hline Met/Met & $9(53 \%)$ & $27(54 \%)$ & 1.05 & 0.93 & 0.33 & 0.45 \\
\hline Met/Val & $7(41 \%)$ & $22(44 \%)$ & \multicolumn{4}{|c|}{$\chi^{2} \mathrm{P}$ value } \\
\hline $\mathrm{Val} / \mathrm{Val}$ & $1(6 \%)$ & $1(2 \%)$ & \multicolumn{4}{|c|}{0.1} \\
\hline
\end{tabular}

Genetics and Molecular Research 15 (3): gmr.15038717 
Table 3. CPT2 haplotype distribution in cases and controls Haplotype frequencies of two CPT2 biallelic polymorphisms: p.(Val368Ile) and p.(Met647Val).

\begin{tabular}{l|l|c|c|c|c}
\hline Haplotype & Freq. & Case; control ratio counts & Case; control frequencies & Chi square & P value \\
\hline 368Val/647Met & 0.453 & $15.7: 18.3 ; 45.0: 55.0$ & $0.461 ; 0.450$ & 0.013 & 0.9089 \\
\hline 368Ile/647Met & 0.308 & $9.2: 24.8 ; 32.0: 68.0$ & $0.271 ; 0.320$ & 0.287 & 0.5921 \\
\hline 368lle/647Val & 0.215 & $7.8: 26.2 ; 21.0: 79.0$ & $0.229 ; 0.210$ & 0.055 & 0.8147 \\
\hline 368Val/647Val & 0.025 & $1.3: 32.7 ; 2.0: 98.0$ & $0.039 ; 0.020$ & 0.363 & 0.5468 \\
\hline
\end{tabular}

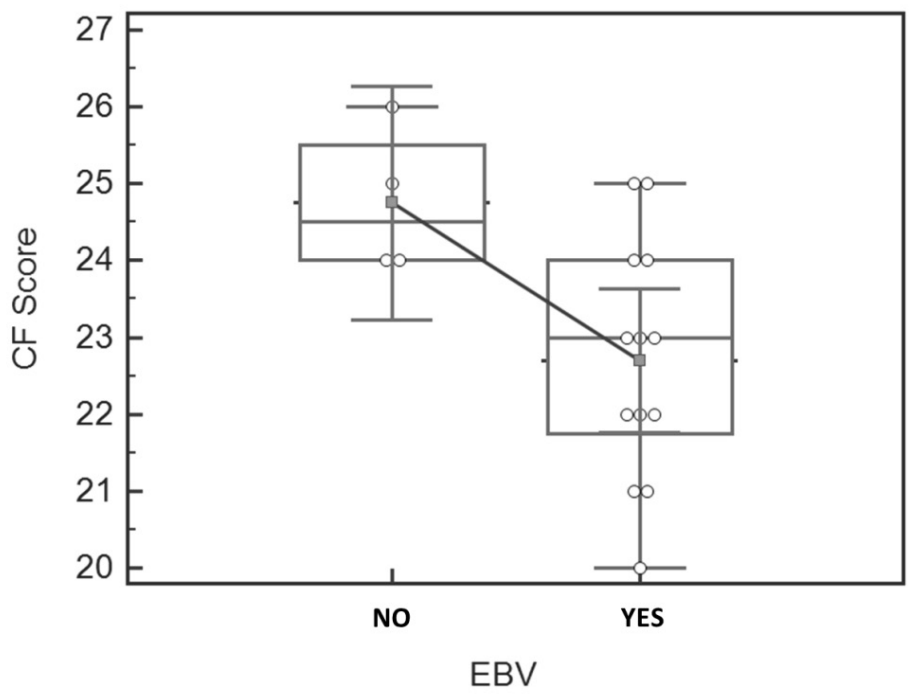

Figure 1. Distribution of EBV trigger-factors in relation to CF score. Abbreviations: EBV, Epstein-Barr virus; CF, chronic fatigue; bars indicate $95 \%$ confidence interval; $\mathrm{x}$-axis represents $\mathrm{CF}$ syndrome trigger factor (calculated as single samples divided by EBV history as CF syndrome trigger factor); $y$-axis represents the CF Score (range 0-26).

\section{DISCUSSION}

CFS is a complex, debilitating disease with a wide range of symptoms of unclear etiology. Genetic involvement is suggested in familial forms of the disease, which was shown by our patient cohort. The study was inspired by the knowledge that mutations in three metabolic genes cause diseases with very similar symptoms to those of CFS. This syndrome is still diagnosed by exclusion, and only genetic tests can reveal whether a patient has myopathy due to myoadenylate deaminase deficiency, carnitine palmitoyltransferase II deficiency, or McArdle disease.

None of our 17 patients diagnosed with CFS carried a mutation in any of the three genes that could alter their diagnosis. Only the synonymous variation p.(Phe602Phe) in the CPT2 gene was found in case 11. This variation has a very low frequency in the Caucasian population, as stated by NCBI (http://www.ncbi.nlm.nih.gov) and the Exome Variant Server (http://evs.gs.washington.edu/EVS) (0.03 and $0.4 \%$ respectively). 
A search for splicing variations using the on-line Human Splicing Finder software version 3 (http://www.umd.be/HSF3/) (Desmet et al., 2009) revealed a potential alternative splicing pattern, however, little is known regarding the functional significance of this variation. Moreover, further diagnostic tests in patient 11 revealed signs of widespread inflammation and multisystemic neuropathology that sustain a differential diagnosis of myalgic encephalomyelitis.

Three non-synonymous polymorphisms in AMPD1 and CPT2 genes were found. However, case-control evaluations did not reveal differences in the genetic distribution of these polymorphisms between the two groups. It needs to be noted that the sample size, especially for the patient group, is very limited to support any conclusion with certainty. Our results showed that polymorphism distributions in cases and controls were in line with those reported in the Exome Variant Server, which included data from 4300 healthy Caucasian subjects. According to this database, approximately $76 \%$ are homozygous $(\mathrm{Gln} / \mathrm{Gln})$ for $A M P D 1$ p. $\left(\mathrm{Gln} 45^{*}\right), 22 \%$ are heterozygous $(\mathrm{Gln} / *)$, and $2 \%$ are homozygous for the polymorphism $(* / *) ; 21 \%$ are homozygous (Val/Val) for CPT2 p.(Val368Ile), $50 \%$ are heterozygous (Val/ Ile), and $29 \%$ are homozygous for the polymorphism (Ile/Ile); $60 \%$ are homozygous (Met/ Met) for CPT2 p.(Met647Val), 35\% are heterozygous (Met/Val), and 5\% are homozygous for the polymorphism ( $\mathrm{Val} / \mathrm{Val})$. However, a higher number of patients are needed to examine the relationship between genetic variability and development or maintenance of CFS.

Disease severity quantified by the CF score is believed to be related to trigger factors, with less severe conditions in subjects reporting viral infections as the trigger. However, this is unlikely to reflect the real situation due to the small number of subjects reporting alternative trigger factors. Despite a number of publications showing that viral infections only explain a small proportion of CFS cases (Gold et al., 1990; Heneine et al., 1994; Mawle et al., 1995), we found that the proportion of patients reporting viral infection as a trigger factor (76\%) was high. This suggested a possible relationship between carnitine deficiency and infections (Mintz, 1995; Famularo et al., 2004). However, we did not find such associations in our study, unless we postulate a role of the immune system, as reported in the literature (Thangasamy et al., 2008; Thangasamy et al., 2009). In addition, the presence of $A M P D 1$ and $C P T 2$ genetic polymorphisms did not seem to exacerbate CFS symptoms or influence progression of the disease. Inflammatory processes could play a role, as indicated by literature (Felger et al., 2012).

In the study, 1/4 of the cases reporting causes other than viral infections was reconsidered for an alternative diagnosis. In particular, the complex clinical presentations and younger age of onset ( 7 years) of case 7 suggested that CFS may be linked to a major genetic syndrome. Medical history indicated that the patient experienced coxalgia and growth pain, which improved at 12 years of age. However, simultaneously, tension headache appeared as a new symptom; the patient also developed orthostatic hypotension due to minimum posterior mitral leaflet prolapse with insignificant regurgitation of the left ventricle. Furthermore, eye problems since adolescence resulted in a corneal transplant at 24 years for stage 4 keratoconus, which is currently under control. The patient also has iron deficiency anemia, hypoglycemia, and is genetically predisposed to celiac disease due to HLA-DQA $1 * 05$ and HLA-DQB $1 * 02$ susceptibility alleles. Lastly, the patient shows sliding hiatal hernia with evidence of bile reflux gastropathy, neurogenic pain in right tibialis anterior, high pain sensitivity, dust-mite and food allergies, slight muscle stiffness, minor cognitive disorders, and frequent sense of hunger. It was found that a cousin of the patient has similar but milder symptoms; the parents were invited to seek genetic counseling.

Genetics and Molecular Research 15 (3): gmr.15038717 
In conclusion, our study show that these metabolic genes are not related to CFS onset, susceptibility, or severity. However, we cannot exclude the possibility that other genes may be involved as multifactorial traits, participating in a cascade of events triggered by external causes.

In contrast with other studies, we emphasize the role of viral infections as a substantial trigger factor for CFS. Concomitant symptoms of depression have been reported because of physical disability associated with CFS, leading to gradual social isolation and a sense of resignation. They cannot be considered a trigger for CFS. The patients and their parents interviewed in this study were determined to fight for a better quality of life; depression only occurred after years of negligible improvement.

\section{Conflicts of interest}

The authors declare no conflict of interest.

\section{ACKNOWLEDGMENTS}

We are grateful to Helen Ampt for revising the manuscript and members of the CFS Patients Association (Associazione Malati CFS - AMCFS onlus) for their support regarding this study.

\section{REFERENCES}

Barrett JC, Fry B, Maller J and Daly MJ (2005). Haploview: analysis and visualization of LD and haplotype maps. Bioinformatics 21: 263-265.http://dx.doi.org/10.1093/bioinformatics/bth457

Bonnefont JP, Djouadi F, Prip-Buus C, Gobin S, et al. (2004). Carnitine palmitoyltransferases 1 and 2: biochemical, molecular and medical aspects. Mol. Aspects Med. 25: 495-520.http://dx.doi.org/10.1016/j.mam.2004.06.004

Cięszczyk P, Eider J, Ostanek M, Leońska-Duniec A, et al. (2011). Is the C34T polymorphism of the AMPD1 gene associated with athlete performance in rowing? Int. J. Sports Med. 32: 987-991. http://dx.doi.org/10.1055/s-0031-1283186

Corti S, Bordoni A, Ronchi D, Musumeci O, et al. (2008). Clinical features and new molecular findings in Carnitine Palmitoyltransferase II (CPT II) deficiency. J. Neurol. Sci. 266: 97-103. http://dx.doi.org/10.1016/j.jns.2007.09.015

Cruciani RA, Revuelta M, Dvorkin E, Homel P, et al. (2015). L-carnitine supplementation in patients with HIV/AIDS and fatigue: a double-blind, placebo-controlled pilot study. HIV AIDS (Auckl.) 7: 65-73. http://dx.doi.org/10.2147/ HIV.S66695

Desmet FO, Hamroun D, Lalande M, Collod-Béroud G, et al. (2009). Human Splicing Finder: an online bioinformatics tool to predict splicing signals. Nucleic Acids Res. 37: e67. http://dx.doi.org/10.1093/nar/gkp215

Famularo G, De Simone C, Trinchieri V and Mosca L (2004). Carnitines and its congeners: a metabolic pathway to the regulation of immune response and inflammation. Ann. N. Y. Acad. Sci. 1033: 132-138. http://dx.doi.org/10.1196/ annals. 1320.012

Felger JC, Cole SW, Pace TW, Hu F, et al. (2012). Molecular signatures of peripheral blood mononuclear cells during chronic interferon- $\alpha$ treatment: relationship with depression and fatigue. Psychol. Med. 42: 1591-1603. http://dx.doi. org $/ 10.1017 / \mathrm{S} 0033291711002868$

Finocchiaro G, Taroni F, Rocchi M, Martin AL, et al. (1991). cDNA cloning, sequence analysis, and chromosomal localization of the gene for human carnitine palmitoyltransferase. Proc. Natl. Acad. Sci. USA 88: 661-665. http:// dx.doi.org/10.1073/pnas.88.2.661

Fukuda K, Straus SE, Hickie I, Sharpe MC, et al.; International Chronic Fatigue Syndrome Study Group (1994). The chronic fatigue syndrome: a comprehensive approach to its definition and study. Ann. Intern. Med. 121: 953-959. http://dx.doi.org/10.7326/0003-4819-121-12-199412150-00009

Gellera C, Verderio E, Floridia G, Finocchiaro G, et al. (1994). Assignment of the human carnitine palmitoyltransferase II gene (CPT1) to chromosome 1p32. Genomics 24: 195-197. http://dx.doi.org/10.1006/geno.1994.1605

Gold D, Bowden R, Sixbey J, Riggs R, et al. (1990). Chronic fatigue. A prospective clinical and virologic study. JAMA 264: 48-53.http://dx.doi.org/10.1001/jama.1990.03450010052029

Genetics and Molecular Research 15 (3): gmr.15038717 
Heneine W, Woods TC, Sinha SD, Khan AS, et al. (1994). Lack of evidence for infection with known human and animal retroviruses in patients with chronic fatigue syndrome. Clin. Infect. Dis. 18 (Suppl 1): S121-S125. http://dx.doi. org/10.1093/clinids/18.Supplement_1.S121

Huang H, Song L, Zhang H, Zhang H, et al. (2013). Influence of L-carnitine supplementation on serum lipid profile in hemodialysis patients: a systematic review and meta-analysis. Kidney Blood Press. Res. 38: 31-41. http://dx.doi. org $/ 10.1159 / 000355751$

Isackson PJ, Bennett MJ and Vladutiu GD (2006). Identification of 16 new disease-causing mutations in the CPT2 gene resulting in carnitine palmitoyltransferase II deficiency. Mol. Genet. Metab. 89: 323-331.http://dx.doi.org/10.1016/j. ymgme.2006.08.004

Kerner J and Hoppel C (2000). Fatty acid import into mitochondria. Biochim. Biophys. Acta 1486: 1-17. http://dx.doi. org/10.1016/S1388-1981(00)00044-5

Kuratsune H, Yamaguti K, Takahashi M, Misaki H, et al. (1994). Acylcarnitine deficiency in chronic fatigue syndrome. Clin. Infect. Dis. 18 (Suppl 1): S62-S67.http://dx.doi.org/10.1093/clinids/18.Supplement 1.S62

Lee BJ, Lin JS, Lin YC and Lin PT (2014). Effects of L-carnitine supplementation on oxidative stress and antioxidant enzymes activities in patients with coronary artery disease: a randomized, placebo-controlled trial. Nutr. J. 13: 79. http://dx.doi.org/10.1186/1475-2891-13-79

Longo N, Amat di San Filippo C and Pasquali M (2006). Disorders of carnitine transport and the carnitine cycle. Am. J. Med. Genet. Part C 142C: 77-85.

Lucia A, Martin MA, Esteve-Lanao J, Juan AF, et al. (2009). C34T mutation of the AMPD1 gene in an elite white runner. BMJ Case Rep. 2009 pii: bcr07.2008.0535.

Mawle AC, Nisenbaum R, Dobbins JG, Gary HE, Jr., et al. (1995). Seroepidemiology of chronic fatigue syndrome: a casecontrol study. Clin. Infect. Dis. 21: 1386-1389. http://dx.doi.org/10.1093/clinids/21.6.1386

McArdle B (1951). Myopathy due to a defect in muscle glycogen breakdown. Clin. Sci. 10: 13-35.

Mintz M (1995). Carnitine in human immunodeficiency virus type 1 infection/acquired immune deficiency syndrome. $J$. Child Neurol. 10 (Supp1 2): S40-S44.

Myhill S, Booth NE and McLaren-Howard J (2009). Chronic fatigue syndrome and mitochondrial dysfunction. Int. J. Clin. Exp. Med. 2: 1-16.

Morisaki T, Gross M, Morisaki H, Pongratz D, et al. (1992). Molecular basis of AMP deaminase deficiency in skeletal muscle. Proc. Natl. Acad. Sci. USA 89: 6457-6461.http://dx.doi.org/10.1073/pnas.89.14.6457

Rubio JC, Martín MA, Campos Y, Auciello R, et al. (2000). A missense mutation W797R in the myophosphorylase gene in a Spanish patient with McArdle's disease. Muscle Nerve 23: 129-131. http://dx.doi.org/10.1002/(SICI)10974598(200001)23:1<129::AID-MUS20>3.0.CO;2-F

Taroni F, Verderio E, Fiorucci S, Cavadini P, et al. (1992). Molecular characterization of inherited carnitine palmitoyltransferase II deficiency. Proc. Natl. Acad. Sci. USA 89: 8429-8433. http://dx.doi.org/10.1073/ pnas.89.18.8429

Thangasamy T, Subathra M, Sittadjody S, Jeyakumar P, et al. (2008). Role of L-carnitine in the modulation of immune response in aged rats. Clin. Chim. Acta 389: 19-24. http://dx.doi.org/10.1016/j.cca.2007.11.013

Thangasamy T, Jeyakumar P, Sittadjody S, Joyee AG, et al. (2009). L-carnitine mediates protection against DNA damage in lymphocytes of aged rats. Biogerontology 10: 163-172. http://dx.doi.org/10.1007/s10522-008-9159-1

Thuillier L, Rostane H, Droin V, Demaugre F, et al. (2003). Correlation between genotype, metabolic data, and clinical presentation in carnitine palmitoyltransferase 2 (CPT2) deficiency. Hum. Mutat. 21: 493-501. http://dx.doi. org/10.1002/humu.10201

Tol VA (1975). Aspects of long-chain acyl-COA metabolism. Mol. Cell. Biochem. 7: 19-31. http://dx.doi.org/10.1007/ BF01732160

Tsujino S, Shanske S and DiMauro S (1993). Molecular genetic heterogeneity of myophosphorylase deficiency (McArdle's disease). N. Engl. J. Med. 329: 241-245. http://dx.doi.org/10.1056/NEJM199307223290404

Tsujino S, Shanske S, Nonaka I and DiMauro S (1995). The molecular genetic basis of myophosphorylase deficiency (McArdle's disease). Muscle Nerve Suppl. 3 (Suppl. 3): S23-S27.http://dx.doi.org/10.1002/mus.880181407

Wessely S and Powell R (1989). Fatigue syndromes: a comparison of chronic "postviral" fatigue with neuromuscular and affective disorders. J. Neurol. Neurosurg. Psychiatry 52: 940-948. http://dx.doi.org/10.1136/jnnp.52.8.940

Genetics and Molecular Research 15 (3): gmr.15038717 